\title{
Description of Warileya lumbrerasi n. sp. (Diptera: Psychodidae) from Peru
}

\author{
Elena Ogusuku/ ${ }^{+}$, J Enrique Perez, Clive R Davies*, Pablo Villaseca \\ Instituto de Medicina Tropical Alexander von Humboldt, Universidad Peruana Cayetano Heredia, A. P. 4314, \\ Lima-100, Peru *London School of Hygiene and Tropical Medicine, London, UK
}

Warileya lumbrerasi $n . s p$. is described from the northern Peruvian Andes. This species was collected inside houses, and is the seventh species described within the genus Warileya Hertig, 1948.

Key words: Warileya lumbrerasi - new species - Psychodidae - Peru

A new species of phlebotomine sandfly belonging to the genus Warileya Hertig, 1948 (Diptera: Psychodidae: Phlebotominae) described with the name Warileya lumbrerasi $\mathrm{n}$. sp., is the seventh described from this genus, which includes W. fourgassiensis (Le Pont \& Desjeux 1984), W. hertigi (Fairchild 1949), W. nigrosacculus (Fairchild \& Hertig 1951), W. phlebotomanica (Hertig 1948), W. rotundipennis (Fairchild \& Hertig 1951) and W. yungasi (Velasco \& Trapido 1974). Of these species, only W. phlebotomanica has previously been reported in Peru (Bermudez et al. 1993).

\section{MATERIALS AND METHODS}

The sandflies examined in this paper were collected in several localities of the Province of Huancabamba, in the Department of Piura. This area is geographically located at $5^{\circ} \mathrm{SL}, 80^{\circ} \mathrm{WL}$ approximately. Sandfly collections were from 17:30 to 22:00 hr inside houses with CDC light traps.

Sandflies were treated with $10 \% \mathrm{NaOH}$, and mounted in slides with Canada Balsam.

Up to ten specimens of each sex of $W$. lumbrerasi were selected for measuring their morphological parts, averages and the standard deviation (SD) were obtained for each part measured (Tables I, II). Otherwise stated, all measurements are given in $\mu \mathrm{m}$.

The description of $W$. lumbrerasi n. sp. presented is based on the standard format designed by the CIPA Group (Bermudez et al. 1991), and provides measurements on a wide range of characters.

${ }^{+}$Corresponding author. Fax: +51-14-823404

Received 26 January 1996

Accepted 23 May 1996

\section{DESCRIPTION}

Warileya lumbrerasi $\mathrm{n}$. sp.

Male: the general color is homogeneous pale brown. Body size $2.3 \mathrm{~mm}$ approximately. Head frons length 279 , clipeus 153 , eye separation 171 , interocular suture complete, labrum 314.6, palpal formula: 1/3/4/2/5, 2.9 times longer than labrum, $\mathrm{P} 5$ as long as the labrum; ratio $\mathrm{P} 5 / \mathrm{P} 3+\mathrm{P} 4=0.95$. Antennae: F1 346.5 long, ratio F14/F13 > 1, ascoids short without proximal projection. Wings: 957 width, R5 length 1353. Genitalia: as drawn in Fig. 1. Ejaculatory filament long 776.6, total pump length 242 (piston alone 206.8) (Fig. 1e). Ratio ejaculatory filaments/pump=3; terminal tip of the filaments very faint (Fig. 1f). Aedeagus simple with truncated tips. Lateral lobe simple 374 long and 26.4 width. Paramere simple with 3 strong setae in the tip. Coxite small, wider than longer, with 2 linear tufts, tuft 1 (inner) with 9 pairs of setae, and tuft 2 (outer) with 5-6 pairs of setae continued by 10 setae in a single line (Fig. 1c). Style length 351, with 3 terminal spines, formula $1 / 2$.

Female: general color as the male. Body size 2.65 $\mathrm{mm}$ approximately. Head frons length 319.5 , clipeus 189 , eyes separation is 189 , interocular suture complete, labrum 432 long, palpal formula: 1/3/4/2/5, 2.6 times longer than labrum, P5 slightly shorter than labrum; ratio $\mathrm{P} 5 / \mathrm{P} 3+\mathrm{P} 4=1$. Cibarium without horizontal teeth, only small lateral teeth, pharynx simple. Antennae: F1 292.5 long, ratio F14/F13 > 1, ascoids as the male (Fig. 2d). Wings: 1056 width, R5 length 1518. Genitalia: cerci simple, 135 long; spermathecae and individual ducts very long: 479.6 total length. Longitudinal ducts simple, length 272.8. Spermathecae as shown in Fig. 2, 206.8 long and 17.6 wide, a very clear sclerotized basal part, with annulations in the spermatheca body, and head of the spermatheca long. Common duct very short, 30.8 long.

Types: the male holotype was collected using a CDC light trap inside a house in the locality of El Higuerón at 1140 m of altitude, on 23 May, 1992, 

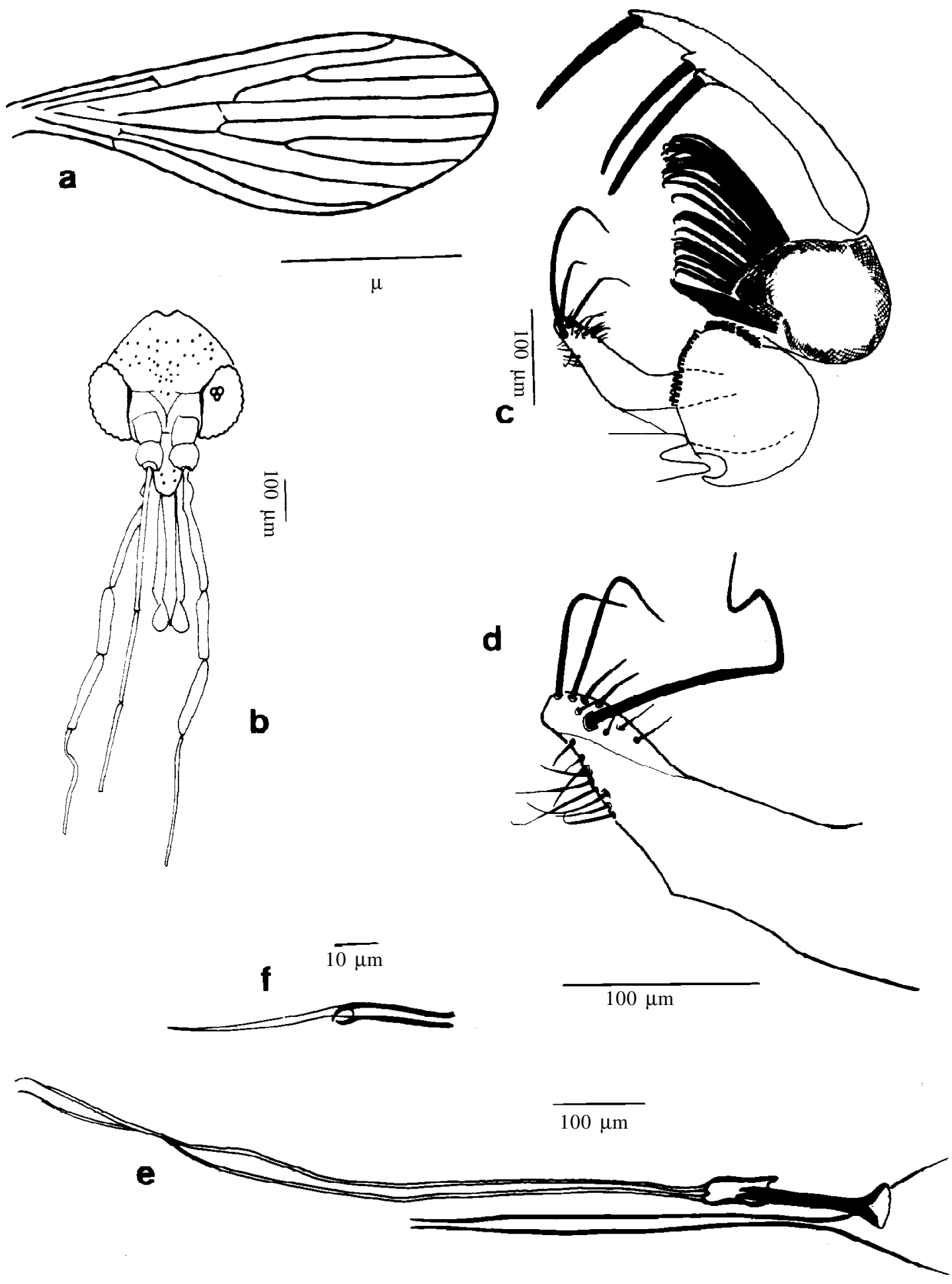

Fig. 1: male of

n. sp. a: wing, b: head, c: genitalia, d: detail of paramere, e: genital pump and ejaculatory filaments, f: detail of ejaculatory filament tip. 

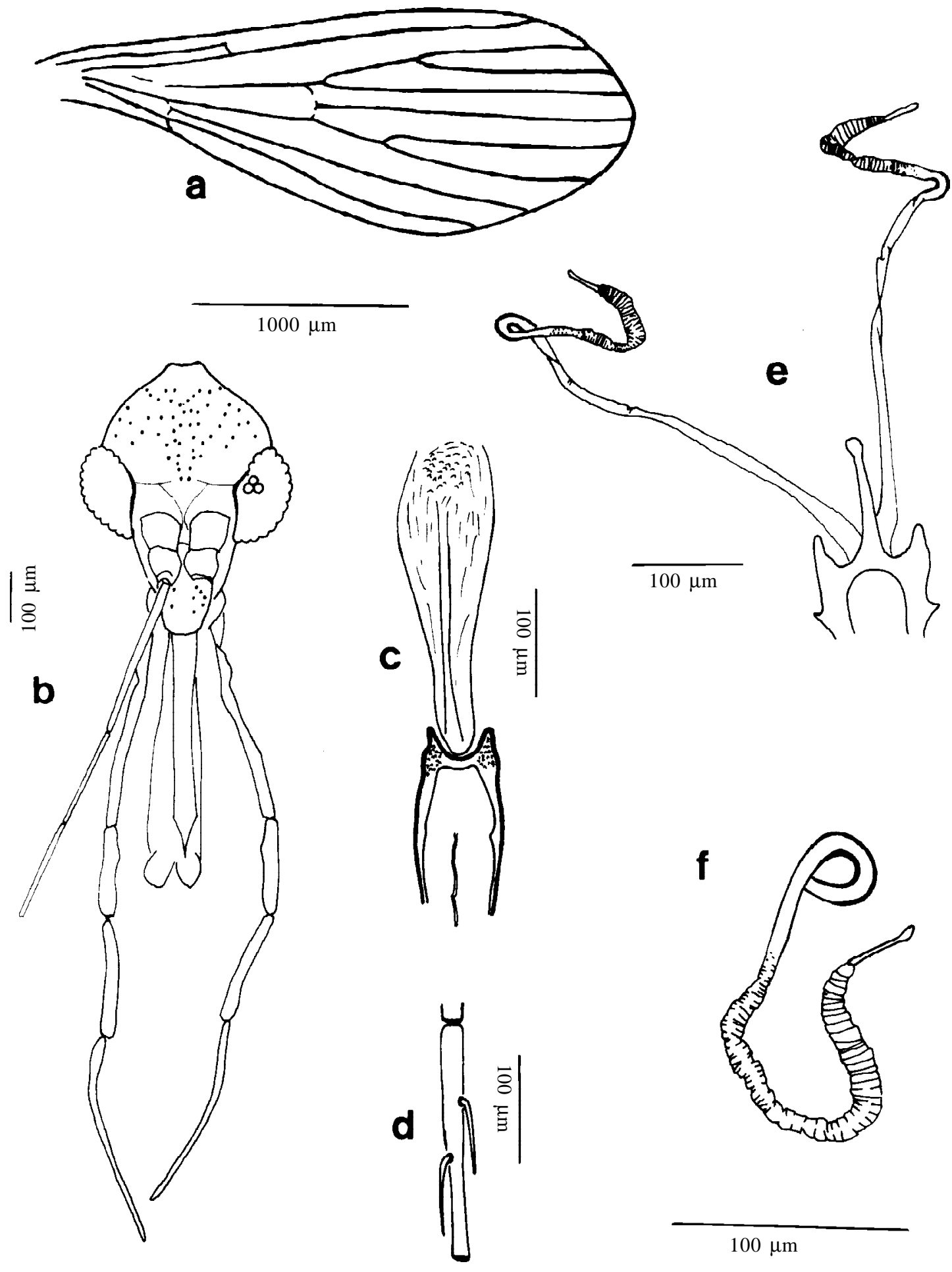

Fig. 2: female of Warileya lumbrerasi n. sp. a: wing, b: head, c: cibarium and pharynx, d: detail of second flagellomere, e: spermatheca, f: detail of spermatheca body. 
by $\mathrm{P}$ Villaseca, and the female allotype was collected using a CDC light trap inside a house in El Higuerón, on 23 May, 1992, by P Villaseca. Paratypes: three males collected in El Higuerón, on 23 May, 1992; five males collected in the same locality on 24 May, 1992; six males from Chamelico collected on 30 May, 1992. Two females collected in El Higuerón, on 25 May, 1992, one female from Chamelico, on 30 May, 1992, three females from Pizarrumi on 29 May, 1992, one female on 21 February, 1993 and two females on 23 February, 1993. All known specimens of $W$. lumbrerasi have been collected in the district of Canchaque, Huancabamba Province, Department of Piura.

All the material of $W$. lumbrerasi $\mathrm{n}$. sp. (males and females) was collected using CDC light traps placed inside houses and operated overnight. It is remarkable that several individuals were engorged when collected. W. lumbrerasi $\mathrm{n}$. sp. coexist with W. phlebotomanica in the localities which were collected: El Higuerón, Chamelico and Pizarrumi, in the Province of Huancabamba, Department of Piura, Peru.

The name lumbrerasi is given to this species in honour of Dr Hugo Lumbreras Cruz (1924-1985), founder of our Institute, who devoted his life to teaching and strengthening of research in Tropical diseases in Peru.

The type material is deposited in the Laboratory of Entomology, Instituto de Medicina Tropical Alexander von Humboldt, Universidad Peruana Cayetano Heredia, Lima, Peru. Male and female paratypes will be deposited in the Department of Entomology, Museo de Historia Natural, Universidad Nacional Mayor de San Marcos, Lima, Peru and the Entomology Section, British Museum (Natural History), UK.

Tables I and II show the measurements (in $\mu \mathrm{m}$ ) of the morphological parts of both $W$. lumbrerasi n. sp. and W. phlebotomanica.

TABLE I

Measurements of males of Warileya lumbrerasi and W. phlebotomanica

\begin{tabular}{|c|c|c|c|c|c|c|}
\hline & \multirow[t]{2}{*}{$\mathrm{n}$} & \multicolumn{2}{|c|}{ W. lumbrerasi } & \multirow[t]{2}{*}{$\mathrm{n}$} & \multicolumn{2}{|c|}{ W. phlebotomanica } \\
\hline & & Avg & SD & & Avg & SD \\
\hline \multicolumn{7}{|l|}{ HEAD } \\
\hline Frons & 10 & 272.7 & 14.0 & 4 & 260.9 & 7.2 \\
\hline Clipeus & 10 & 146.4 & 10.1 & 4 & 156.4 & 12.1 \\
\hline Labrum & 10 & 302.4 & 19.8 & 4 & 320.4 & 10.1 \\
\hline \multicolumn{7}{|l|}{ PALPUS } \\
\hline P1 & 10 & 47.2 & 3.7 & 4 & 54.2 & 1.1 \\
\hline P2 & 10 & 220.5 & 15.3 & 4 & 230.6 & 14.7 \\
\hline P3 & 10 & 160.3 & 12.9 & 4 & 184.5 & 10.1 \\
\hline P4 & 10 & 179.6 & 17.9 & 4 & 222.8 & 22.6 \\
\hline P5 & 10 & 334.9 & 49.4 & 4 & 420.3 & 74.9 \\
\hline \multicolumn{7}{|c|}{ ANTENNA } \\
\hline $\mathrm{F} 1$ & 10 & 330.3 & 28.6 & 4 & 303.1 & 14.2 \\
\hline $\mathrm{F} 2$ & 10 & 208.0 & 17.1 & 4 & 181.2 & 12.1 \\
\hline \multicolumn{7}{|l|}{ WING } \\
\hline Width & 10 & 921.8 & 74.4 & 4 & 1089.0 & 78.9 \\
\hline R5 & 10 & 1347.5 & 84.4 & 4 & 1507.0 & 160.5 \\
\hline Alfa & 10 & 676.5 & 63.0 & 4 & 717.8 & 70.2 \\
\hline Beta & 10 & 414.7 & 27.4 & 4 & 457.3 & 65.0 \\
\hline Gamma & 10 & 63.8 & 11.8 & 4 & 103.5 & 49.2 \\
\hline Delta & 10 & 390.5 & 54.6 & 4 & 445.8 & 69.4 \\
\hline \multicolumn{7}{|l|}{ LEGS } \\
\hline $\mathrm{F}$ ant. & 8 & 862.1 & 66.9 & 1 & 902.0 & --- \\
\hline F. med. & 7 & 869.0 & 76.7 & 3 & 887.3 & 51.8 \\
\hline F. post. & 7 & 944.4 & 44.9 & 4 & 981.8 & 53.0 \\
\hline T. ant. & 8 & 1691.3 & 80.9 & 1 & 1870.0 & --- \\
\hline T. med. & 6 & 1706.8 & 128.3 & 3 & 1796.7 & 174.5 \\
\hline T. post. & 7 & 1866.9 & 46.0 & 3 & 1976.3 & 199.3 \\
\hline \multicolumn{7}{|c|}{ GENITALIA } \\
\hline Pump & 10 & 227.5 & 12.2 & 4 & 160.2 & 9.1 \\
\hline Ejac. Fil. & 10 & 781.0 & 58.9 & 4 & 259.3 & 11.5 \\
\hline Lat. lobe & 10 & 383.2 & 28.9 & 4 & 275.4 & 9.0 \\
\hline Style & 10 & 351.2 & 14.6 & 4 & 254.1 & 12.6 \\
\hline
\end{tabular}


TABLE II

Measurements of females of Warileya lumbrerasi and W. phlebotomanica

\begin{tabular}{|c|c|c|c|c|c|c|}
\hline & \multirow[t]{2}{*}{$\mathrm{n}$} & \multicolumn{2}{|c|}{ W. lumbrerasi } & \multirow[t]{2}{*}{$\mathrm{n}$} & \multicolumn{2}{|c|}{ W. phlebotomanica } \\
\hline & & Avg & SD & & Avg & SD \\
\hline \multicolumn{7}{|l|}{ HEAD } \\
\hline Frons & 10 & 329.0 & 11.1 & 4 & 300.4 & 17.8 \\
\hline Clipeus & 10 & 187.7 & 11.2 & 4 & 173.3 & 3.9 \\
\hline Labrum & 10 & 439.2 & 19.6 & 4 & 415.1 & 25.8 \\
\hline \multicolumn{7}{|l|}{ PALPUS } \\
\hline $\mathrm{P} 1$ & 10 & 71.1 & 4.8 & 4 & 68.0 & 9.4 \\
\hline $\mathrm{P} 2$ & 10 & 286.2 & 10.6 & 4 & 281.3 & 16.0 \\
\hline P3 & 10 & 189.5 & 10.7 & 4 & 196.9 & 12.8 \\
\hline $\mathrm{P} 4$ & 10 & 220.1 & 18.4 & 4 & 247.5 & 13.5 \\
\hline P5 & 9 & 395.5 & 50.6 & 4 & 519.8 & 51.8 \\
\hline \multicolumn{7}{|l|}{ ANTENNA } \\
\hline $\mathrm{F} 1$ & 10 & 324.5 & 22.3 & 4 & 322.5 & 11.8 \\
\hline $\mathrm{F} 2$ & 10 & 203.0 & 12.2 & 4 & 187.5 & 5.6 \\
\hline $\mathrm{F} 1 / \mathrm{F} 2$ & 10 & 1.6 & 0.4 & 4 & 5.6 & 0.1 \\
\hline \multicolumn{7}{|l|}{ WING } \\
\hline Width & 10 & 1114.3 & 52.5 & 4 & 1190.8 & 155.2 \\
\hline R5 & 10 & 1628.0 & 82.9 & 4 & 1633.5 & 187.5 \\
\hline Alfa & 10 & 839.3 & 69.0 & 4 & 849.8 & 87.0 \\
\hline Beta & 10 & 502.7 & 33.7 & 4 & 473.0 & 49.8 \\
\hline Gamma & 10 & 70.4 & 19.8 & 4 & 82.5 & 44.3 \\
\hline Delta & 10 & 510.4 & 64.6 & 4 & 533.5 & 45.6 \\
\hline \multicolumn{7}{|l|}{ LEGS } \\
\hline F. ant. & 5 & 1012.0 & 42.3 & 3 & 979.0 & 50.0 \\
\hline F. med. & 6 & 990.0 & 38.1 & 4 & 946.0 & 80.4 \\
\hline F. post. & 8 & 1090.4 & 52.0 & 4 & 1078.0 & 106.6 \\
\hline T. ant. & 5 & 1867.8 & 85.3 & 3 & 1899.3 & 22.6 \\
\hline T. med. & 6 & 1818.7 & 101.3 & 4 & 1823.3 & 99.1 \\
\hline T. post. & 8 & 2017.1 & 109.3 & 4 & 2010.3 & 141.5 \\
\hline \multicolumn{7}{|c|}{ GENITALIA } \\
\hline Cercus & 10 & 129.6 & 11.1 & 4 & 129.3 & 8.7 \\
\hline Spermat. & 10 & 258.7 & 40.3 & 3 & 114.0 & 15.9 \\
\hline Ind. Duct & 10 & 303.8 & 75.2 & 2 & 39.6 & 4.4 \\
\hline
\end{tabular}

\section{REMARKS}

The male genitalia of $W$. lumbrerasi are closely related to those of $W$. yungasi in the shape of the paramere and the number of style spines, but differ in the style spine formula, which is $1 / 2$ in $W$. lumbrerasi and 2/1 in W. yungasi. The paramere of $W$. lumbrerasi is similar to that of $W$. phlebotomanica, except that the former has three large setae, whilst the latter has two.

A distinctive character which separates the males of the two Peruvian Warileya species is the length of the genitalia parts. Those of $W$. lumbrerasi are significantly longer than those of $W$. phlebotomanica (Table I), especially the ejaculatory filaments which are three times longer in $W$. lumbrerasi.

The shape of the spermathecae body of $W$. lumbrerasi is closely related to that of $W$. phlebotomanica. The main differences are that the rings are not imbricated in $W$. lumbrerasi, the spermathecal body of $W$. lumbrerasi is twice the length of that of $W$. phlebotomanica, and the individual ducts are seven times longer in $W$. lumbrerasi. W. lumbrerasi also shows heavy chitinization in the basal extreme of the spermatheca body.

Although W. phlebotomanica and $W$. lumbrerasi are sympatric in the Department of Piura, they appear to have distinct geographical distributions in Peru. W. phlebotomanica is widespread throughout the Andean Cordillera, while $W$. lumbrerasi appears to be restricted to the northern section of the Peruvian Cordillera.

\section{ACKNOWLEDGEMENT}

To Dr Carlos Santa Cruz (IMTAvH-UPCH) for his photographic work. 
n. sp. from Peru - E Ogusuku et al.

\section{REFERENCES}

Bermudez H, Dedet J-P, Falcão A, Feliciangeli D, Rangel

M, Ogusuku E, Perez E, Sherlock I, Torrez M, Vignes R, Wolff M (Cipa Group) 1991. Proposition

33

Bermudez H, Dedet J-P, Duncan M, Falcão A, Feliciangeli D, Ferro C, Galati EAB, Gomez E,

E, Perez E, Rangel E, Sherlock I, Torrez M, Vignes R, Wolff M, Young DG (Cipa Group) 1993. A

phlebotomine sandflies of the Americas (CIPA). Presentation and check-list of American species.

Inst Oswaldo Cruz : 221-230.

Fairchild GB 1949. A new fly related to from Panama (Diptera, Psychodidae). Proc Entomol 51

Fairchild GB, Hertig M 1951. Notes on the Phlebotoof Panama (Diptera, Psychodidae) . VIII Two new species of . Ann Entomol Soc Am 44 422-429.

Hertig M 1948. A new genus of bloodsucking Entomol Soc Am 41: 8-16.

Warileya fourgassiensis $\mathrm{n}$.

cavernicole découvert en Guyane française. Cahiers 22

Velasco JH, Trapido 1974. Two new Phlebotominae sandflies from Bolivia and , n. sp.

J Med Ent 11: 433-436 n. sp. (Diptera: Psychodidae). 